\title{
Hypertensive Disorders in Pregnancy and its Diagnosis and Treatment
}

\author{
Dr. Himanshi* \\ Independent Researcher, Sonepat, Haryana, India
}

Received date: June 3, 2021; Accepted date: June 17, 2021; Published date: July 25, 2021

Correspondence to: Dr. Himanshi, Independent Researcher, Sonepat, Haryana, India.

Citation: Himanshi (2021) Hypertensive Disorders in Pregnancy and its Diagnosis and Treatment. J Obst Gynecol Surg 2(1): pp. 1. doi: 10.52916/jogs214015 Copyright: (C2021 Himanshi. This is an open-access article distributed under the terms of the Creative Commons Attribution License, which permits unrestricted use, distribution and reproduction in any medium, provided the original author and source are credited.

W hile motherhood may be a positive and enjoyable experience, many ladies are experiencing suffering, illness, and death. During pregnancy, at delivery, or post-partum around $15 \%$ of pregnant women are expected to develop life-threatening complications and among these Hypertensive Disorders of Pregnancy (HDP) are significant contributors and sufferings [1]. Hypertension term is used to describe high Blood Pressure (BP). Hypertension in pregnancy is defined as: "Systolic blood pressure greater than or adequate to $140 \mathrm{mmHg}$ and/or diastolic blood pressure greater than or adequate to $90 \mathrm{mmHg}$ which usually confirmed within four hours apart measurement". Pre-existing hypertension, Gestational Hypertension (GH), Pre-eclampsia (PE)/eclampsia, and superimposed hypertension are the spectrum of conditions that encompass hypertension disorder in pregnancy. The range in which these conditions occur is from a mild increase in blood pressure at term with no additional signs or symptoms to severe complications with potential for significant maternal, fetal, and neonatal harm. A significant number of women die every year from pregnancy-related causes globally. Hypertensive disorders in pregnancy cause approximately $12 \%$ of maternal deaths. This is the reason why hypertension complications are among the main public health issues worldwide. Hypertensive disorders in pregnancy vary in different populations. This problem is generally more common in developing countries compared to developed countries [2].

BP measurement before pregnancy is necessary for differential diagnosis; otherwise, diagnosis cannot be sure. Chronic hypertension is described as a disturbance detected before 20 weeks of gestation by the American College of Obstetrician and Gynaecologists (ACOG), Royal College of Obstetricians and Gynaecologists (RCOG), Society of Obstetricians and Gynaecologists of Canada (SOGC), Society of Obstetric Medicine of Australia and New Zealand (SOMANZ), in line with ISSHP. Women should be positioned seated, without crossed legs, with feet touching the floor and the back completely resting on the chair during BP measurement. The pressure value can be underestimated because of lying or supine or side position. Women must refrain from talking, consulting the telephone, watching television and reading etc. The arm should not be stretched; it should be at heart level. After at least 5 minutes of sitting position at rest, the first measurement must be taken. The cap should be of the right size and it should not be placed over clothes. BP measurement should be done several times [3].
A reduction in salt intake and weight loss are of proven benefit in non-pregnant hypertensive patients. There is currently no evidence that instituting an exercise program during pregnancy is effective in preventing preeclampsia in at risk individuals, although in an animal model some benefit has been seen. Similarly, no evidence that instituting a weight loss program in pregnancy can prevent preeclampsia. Pharmacologic therapy during pregnancy may prevent progression to severe hypertension and maternal complications while improving fetal maturity by permitting prolongation of pregnancy. In pregnancy, methyldopa is one of the medications with the longest track record. No increased incidence of general health problems or cognitive problems was found from a study on children born to women treated with methyldopa during pregnancy. Methyldopa can have many side effects, including sedation and impaired sleep patterns as it acts centrally by decreasing sympathetic tone. Methyldopa may cause mild elevations of liver enzymes, which can lead to diagnostic confusion with HELLP syndrome. Methyldopa is not a potent BP lowering agent, it is relatively safe. It can be combined with other anti-hypertensives, such as a diuretic to achieve target blood pressure values. Beta-blockers are generally well-tolerated and these are safe in pregnancy. One of the favored therapies for hypertension disorders in pregnancy is labetalol. Labetalol is a non-selective beta-blocker that antagonizes both beta and alpha-1 receptors. Diuretics are the most commonly used medication. A woman can be continued on diuretic medication during pregnancy if she is on a diuretic before pregnancy. But, except for spironolactone, which may have fetal anti-androgen effects [4].

\section{References}

1. Berhe AK, Kassa GM, Fekadu GA, et al. (2018) Prevalence of hypertensive disorders of pregnancy in Ethiopia: a systemic review and meta-analysis. BMC Pregnancy Childbirth 18(1): pp. 34.

2. Hinkosa L, Tamene A, Gebeyehu N (2020) Risk factors associated with hypertensive disorders in pregnancy in Nekemte referral hospital, from July 2015 to June 2017, Ethiopia: a casecontrol study. BMC Pregnancy Childbirth 20(1): pp. 16.

3. Tagetti A, Fava C (2020) Diagnosis of hypertensive disorders in pregnancy: an update. J Lab Precis Med 5(1): pp. 8.

4. Kattah AG, Garovic VD (2013) The management of hypertension in pregnancy. Adv Chronic Kidney Dis 20(3): pp. 229-239. 